\title{
ANALISIS DAN PERANCANGAN SISTEM INFORMASI PENCATATAN DAN PELAPORAN PERSEDIAAN BARANG PAKAI HABIS DI PERANGKAT DAERAH KOTA BANDUNG BERBASIS ONLINE (WEB) DENGAN PENDEKATAN PROGRESSIVE WEB APP (PWA)
}

\author{
Yusup Jauhari Shandi \\ Sekolah Tinggi Manajemen Informatika dan Komputer LIKMI \\ Jl. Ir. H. Juanda Bandung 40132 \\ E-mail : ujshandi@gmail.com
}

\begin{abstract}
ABSTRAK
Pencatatan barang persediaan merupakan bagian dari proses pengamanan administrasi barang persediaan. Proses pengamanan administrasi barang persediaan melalui pencatatan wajib dilaksanakan oleh setiap Perangkat Daerah.Setiap akhir semester dan akhir tahun Perangkat Daerah wajib menyampaikan Laporan barang persediaan kepada BPKA dengan tembusan kepada Inspektorat.

Dengan tidak tersedianya sistem informasi untuk membantu proses pelaporan ini, kegiatan pembuatan laporan diakhir semester menjadi beban yang berat bagi setiap Perangkat Daerah. Oleh karena itu dengan adanya sistem informasi pencatatan dan pelaporan persediaan barang proses pelaporan akan dilakukan dengan mudah dan cepat.

Tidak hanya itu, sistem berbasis online (web) ini diharapkan bisa mengatasi permasalahan kondisi internet yang tidak stabil tanpa mengganggu proses input data oleh perangkat daerah dengan pendekatan Progressive Web App (PWA).
\end{abstract}

Kata kunci : persediaan, pelaporan, pencatatan, pwa, progressive web app

\section{PENDAHULUAN}

Informasi sudah menjadi kebutuhan yang penting diberbagai aspek kegiatan. Keakuratan serta kecepatan penyajian informasi menjadi hal yang tidak kalah penting dari informasi itu sendiri.

Barang persediaan adalah adalah aset lancar dalam bentuk barang atau perlengkapan yang dimaksudkan untuk mendukung kegiatan operasional Pemerintah Daerah, dan barang-barang yang dimaksudkan untuk dijual dan/atau diserahkan dalam rangka pelayanan kepada masyarakat. Pencatatan barang persediaan merupakan bagian dari proses pengamanan administrasi barang persediaan. Proses pengamanan administrasi barang persediaan melalui pencatatan wajib dilaksanakan oleh setiap Perangkat Daerah meliputi:

a. Pengamanan administrasi pencatatan penerimaan barang persediaan; dan

b. Pengamanan administrasi pencatatan pengeluaran barang persediaan.

Proses pencatatan penerimaan dan pengeluaran barang persediaan dilaksanakan langsung pada saat terjadi penerimaan dan/atau pengeluaran barang persediaan. Sistem informasi berbasis online diharapkan bisa membantu proses pencatatan penerimaan dan pengeluaran barang persediaan secara cepat agar bisa langsung dievaluasi atau dipantau oleh stakeholder sistem. Namun dengan adanya kendala di jaringan internet dibeberapa perangkat daerah, maka sistem juga diharapkan bisa mengatasi masalah koneksi internet tersebut agar tidak mengganggu proses input data. 


\section{RAPERWAL NOMOR 17 TAHUN 2019}

Badan Pengelolaan Keuangan dan Aset yang selanjutnya disebut BPKA adalah Badan Pengelolaan Keuangan dan Aset Kota Bandung.Maksud dibentuknya Peraturan Wali Kota ini adalah sebagai pedoman bagi Perangkat Daerah untuk memudahkan dalam menyusun dan melaksanakan pencatatan dan pelaporan barang persediaan. Sedangkan tujuannya adalah terwujudnya pencatatan dan pelaporan barang persediaan secara tertib, efektif, efisien dan akuntabel. Ruang lingkup yang diatur dalam Peraturan Wali Kota ini adalah mengenai:

a. sumber penerimaan barang persediaan;

b. jenis-jenis barang persediaan;

c. pencatatan dan pelaporan barang persediaan; dan

d. inventarisasi fisik

\section{ARSITEKTUR DAN PERANCANGAN SISTEM}

\section{A. Arsistektur Sistem}

Sistem yang akan dibuat bersifat online dan berbasis web. Dikarenakan ada kendala dengan kondisi bandwith internet yang disediakan, maka sistem ini didesign untuk mampu bekerja pada tingkatan bandwith internet yang minim.

\section{B. Progressive Web App (PWA)}

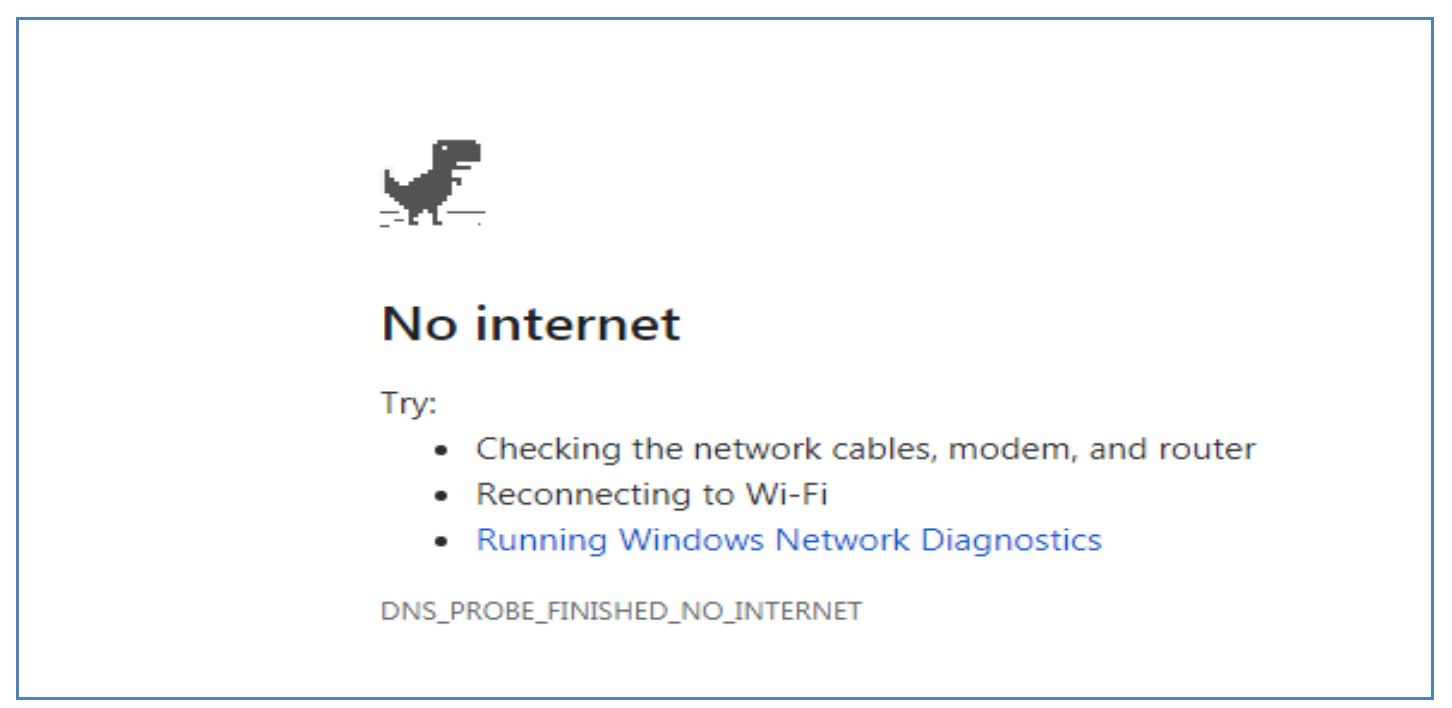

Gambar 1

Pesan Kesalahan Koneksi Internet Tidak Ada

Gambar 1 sering terlihat pada sebuah browser (contoh Chrome), ketika kita sedang bermaksud terhubung ke sebuah halaman web tetapi koneksi internet tidak ada.

"Progressive web apps are not dependent on the user's connection like traditional website are. When a user visit a progressive web app, it will register a service worker" (Tal Ater, 2017)

Browser sebagai palang pintu untuk mengakses aplikasi berbasis web, saat ini sudah di level "Modern Browser" (terutama Google Chrome dan Firefox Mozilla). Dengan diterapkannya teknologi PWA pada sistem informasi di BPKA ini diharapkan tidak mengganggu operasional proses input data walaupun kondisi jaringan internet di suatu perangkat daerah berada pada titik rendah. 


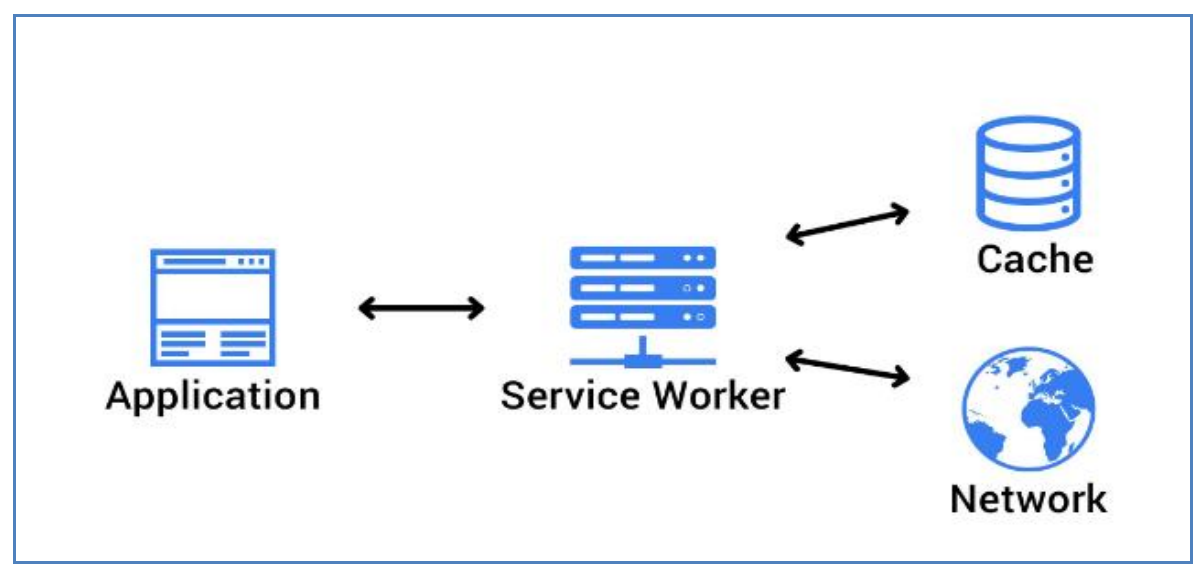

Gambar 2

Skema Kerja Service Worker

(https://www.wisdomgeek.com/wp-content/uploads/2019/06/service-worker-progressiveweb-application.jpeg)

Service Worker memberi jawaban untuk masalah koneksi internet yang terbatas, sisatem akan menyimpan shell (kerangka halaman) dan assets (CSS \& JS) di Cache Storage yang nantinya akan ditampilkan kepada user. Jadi user tidak perlu men-download ulang terus-menerus setiap reload halaman, dan bahkan bisa ditampilkan ketika user sedang offline.

Framework untuk handle server menggunakan PHP Laravel (https://laravel.com/), sedangkan untuk client nya dengan menggunakan Vue.js (https://vuejs.org/) dan untuk databasenya menggunakan MariaDb (atau MySql).

\section{B. Perancancangan Sistem}

Berikut ini adalah Aplikasi Pencatatan Persediaan di BPKA yang tergambar dalam diagram UML.

- USE CASE DIAGRAM

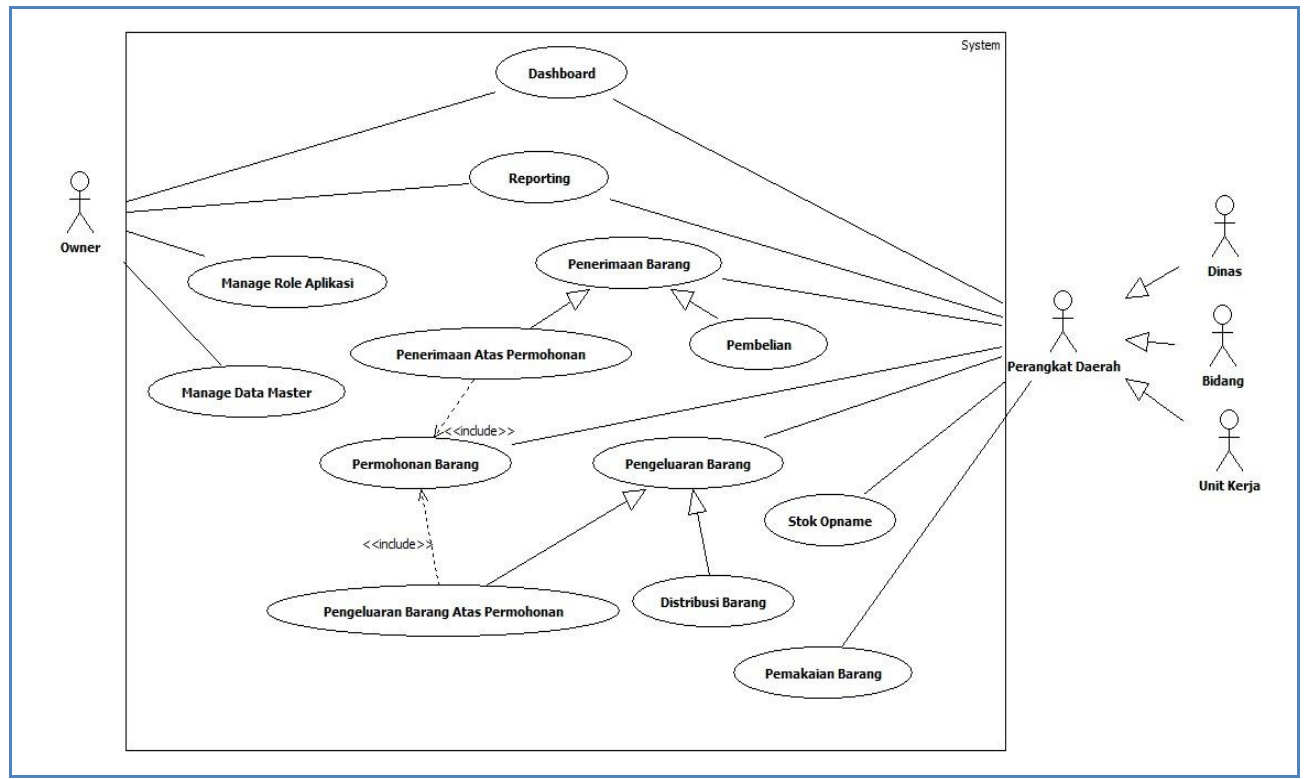

Gambar 3

Use Case Diagram 
Pada Gambar 3 digambarkan aktor dan use case yang terdapat pada aplikasi beserta hubungannya. Berikut adalah daftar aktor serta use case :

a. Aktor

1) Owner, pihak yang memiki aplikasi sekaligus semua data yang ada di aplikasi. Pemanfaatan aplikasi beserta datanya akan digunakan oleh owner sebagai bahan pertanggungjawaban pelaporan ke inspektorat.

2) Perangkat Daerah, user yang menginput data-data transaksional pencatatan masuk atau keluar barang. Terdiri dari :
i. Dinas
ii. Bidang
iii. Unit Kerja

Ketiga aktor di perangkat daerah ini dibedakan dari sisi kepemilikan datanya. Sifat kepemilikan data ataupun transaksi antar perangkat daerah berlaku aturan berjenjang.

b. Use Case

1) Dashboard

Menampilkan ringkasan data transaksi penerimaan dan pengeluaran barang

2) Permohonan barang

Proses pencatatan nota permohonan permintaan barang dari satu perangkat daerah kepada induk perangkat daerahnya.

3) Penerimaan barang

Proses pencatatan penerimaan barang yang terjadi di perangkat daerah. Penerimaan barang ini terdiri dari dua sumber, yaitu : Pembelian (mandiri) dan Hasil distribusi dari perangkat daerah induknya.

4) Pengeluaran barang

Proses pencatatan pengeluaran barang yang terjadi di perangkat daerah. Pengeluaran barang ini terdiri dari : Distribusi dan pengeluaran berdasarkan nota permohonan

5) Stok Opname

Proses pencatatan nilai stok sistem disesuaikan dengan nilai stok secara fisik.

6) Pemakaian barang

Proses pencatatan pemakaian barang di perangkat daerah

- CLASS DIAGRAM

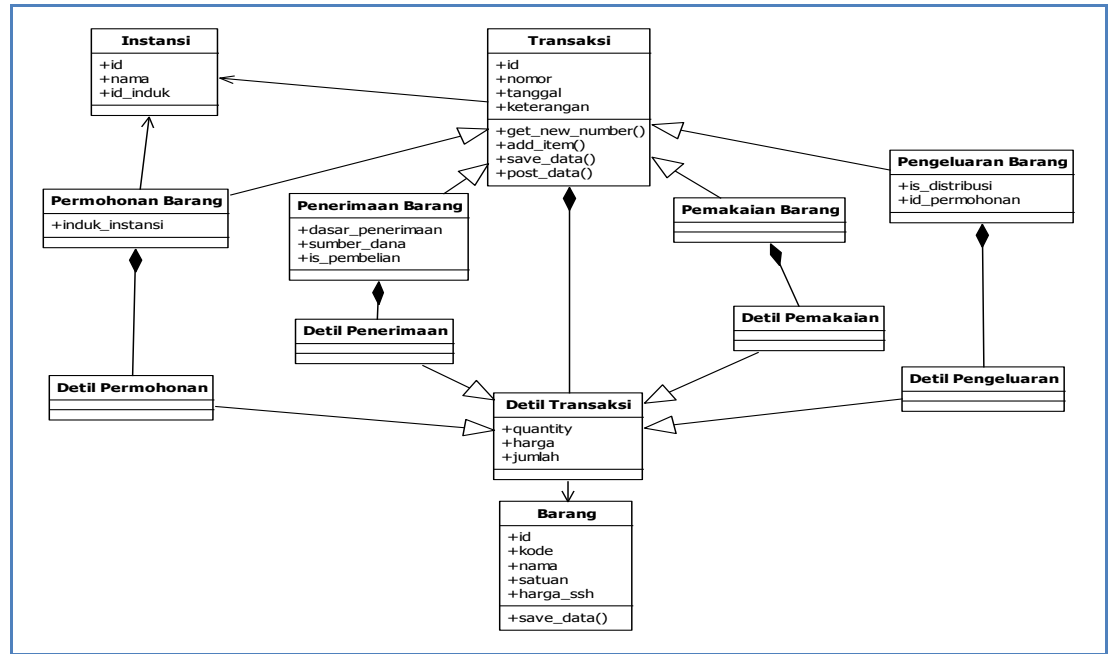

Gambar 4

Class Diagram 
- ACTIVITY DIAGRAM

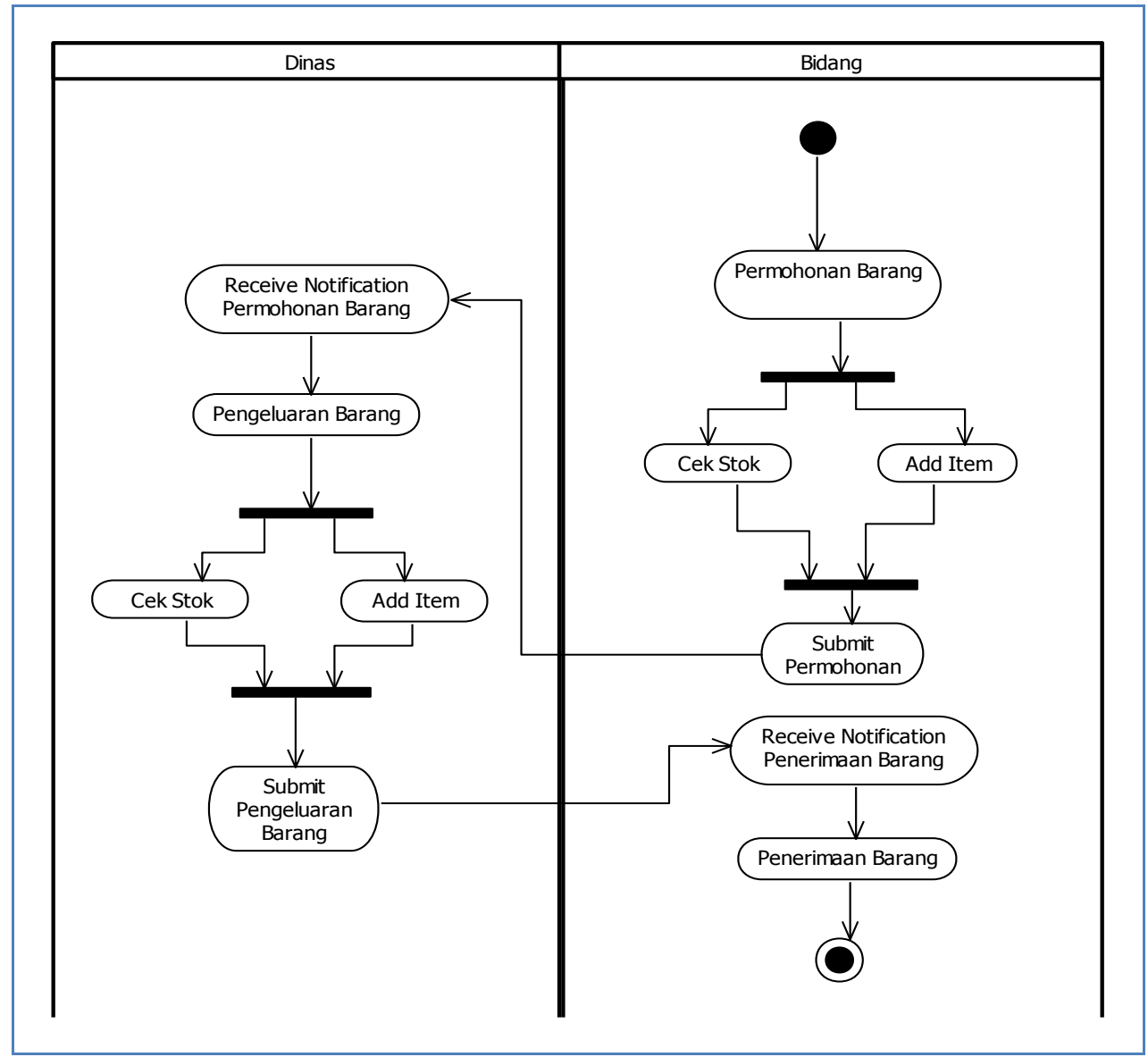

Gambar 5

Activity Diagaram Proses Penerimaan Barang 
- PERANCANGAN DATABASE

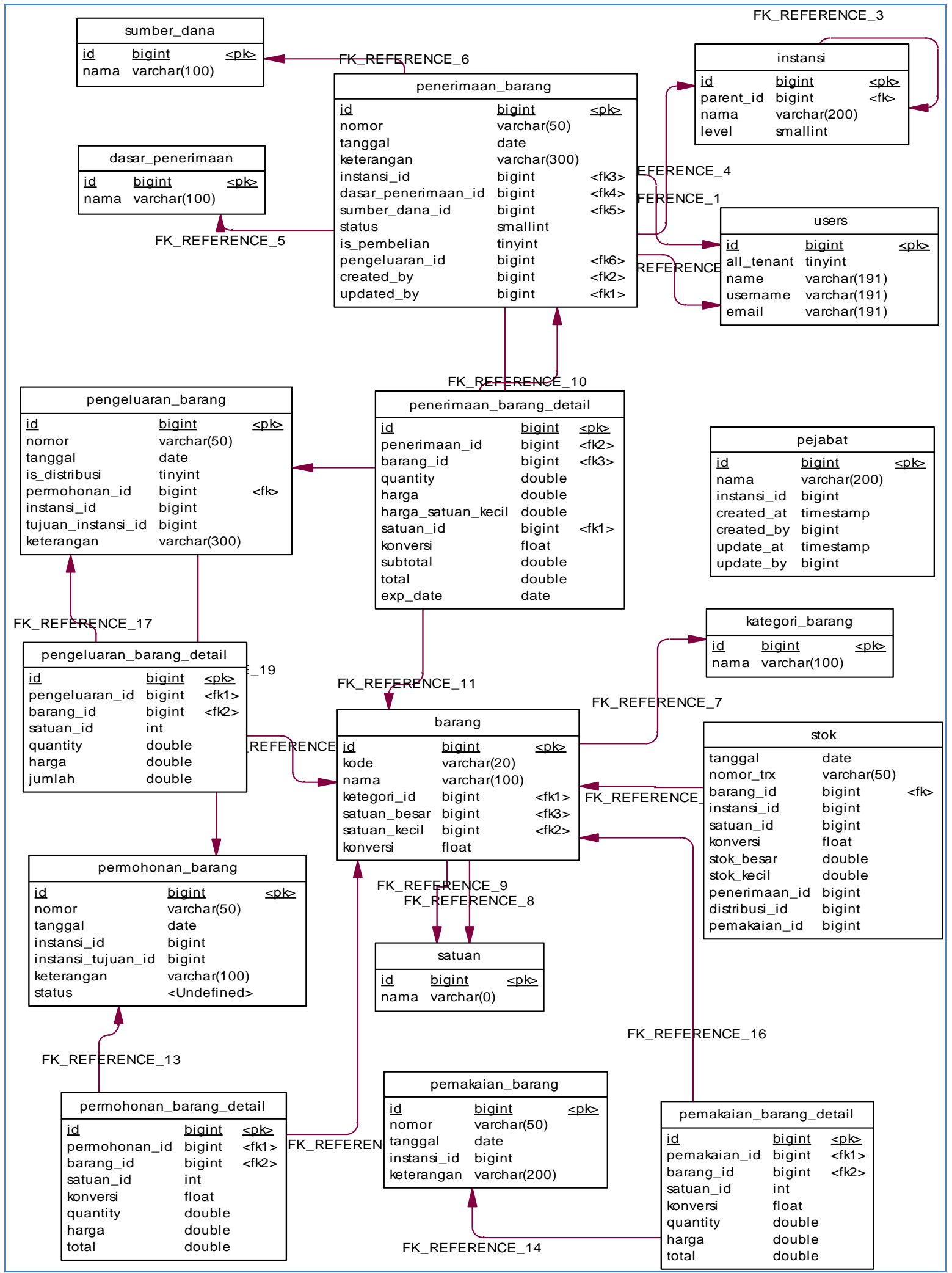

Gambar 6

Skema Database 
- USER INTERFACE DESIGN

Berikut adalah contoh-contoh design interface untuk sistem ini :

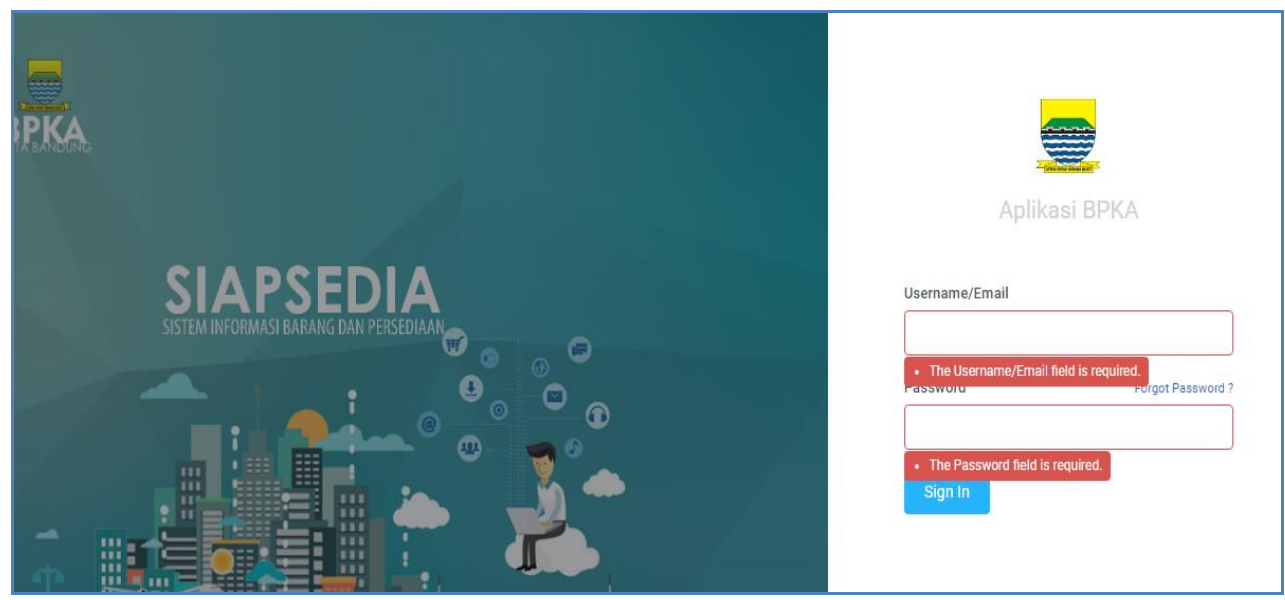

Gambar 7

Antar Muka Login

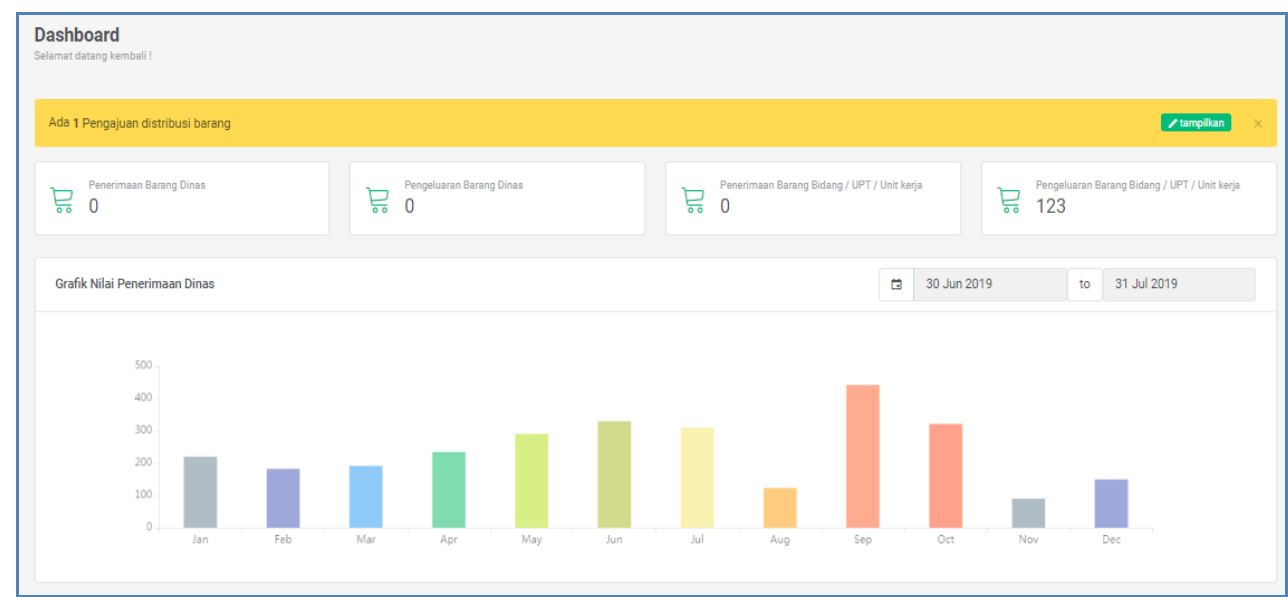

Gambar 8

Antar Muka Dashboard

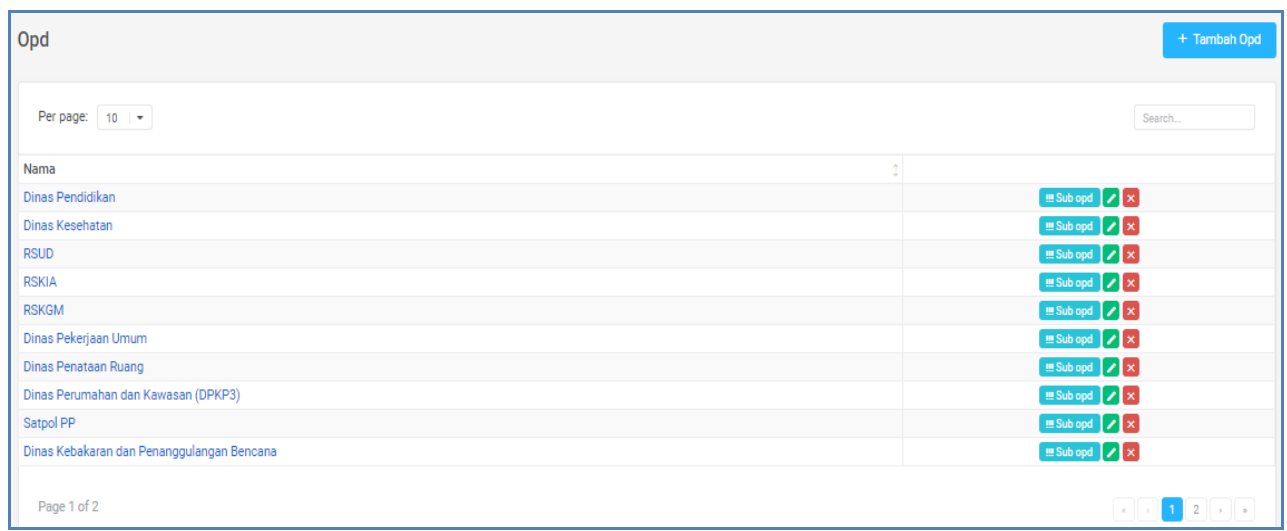

Gambar 9

Antar Muka Master Organisasi Perangkat Daerah 


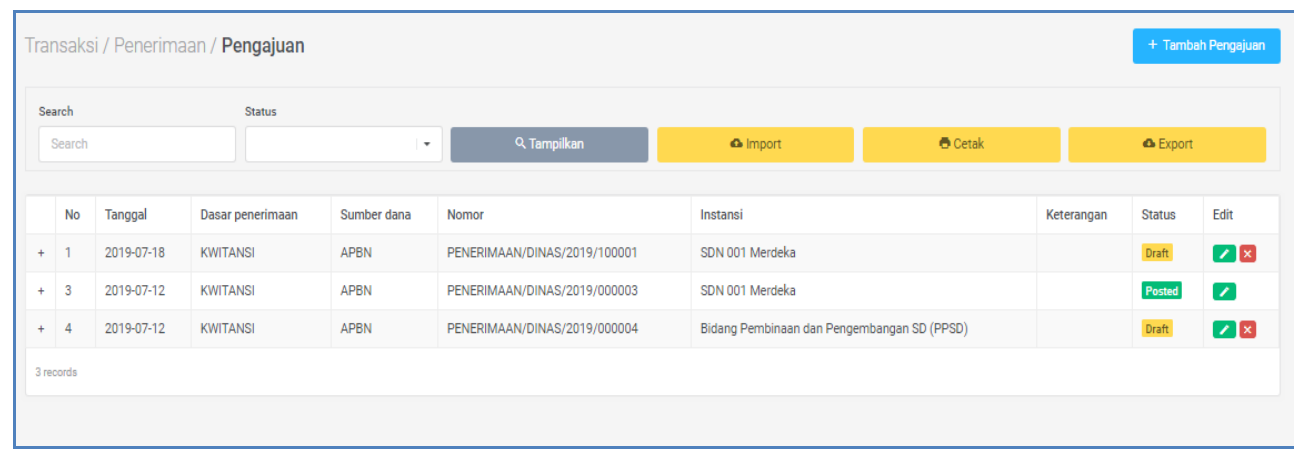

Gambar 10

Antar Muka Pengajuan

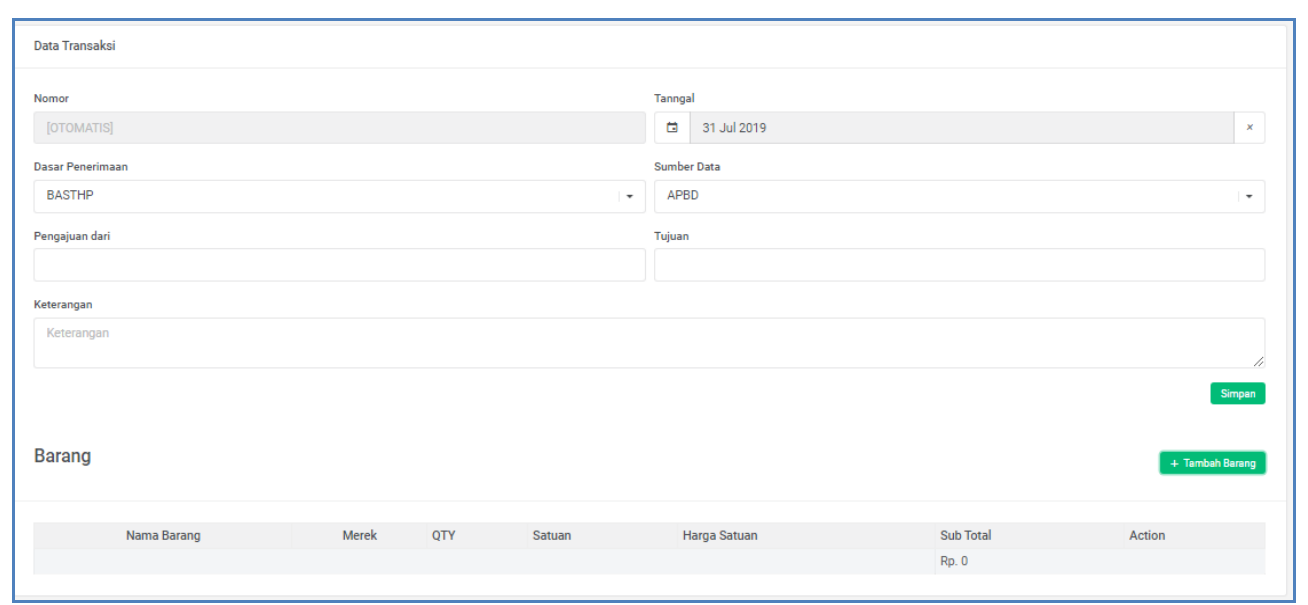

Gambar 11

Antar Muka Permohonan Barang

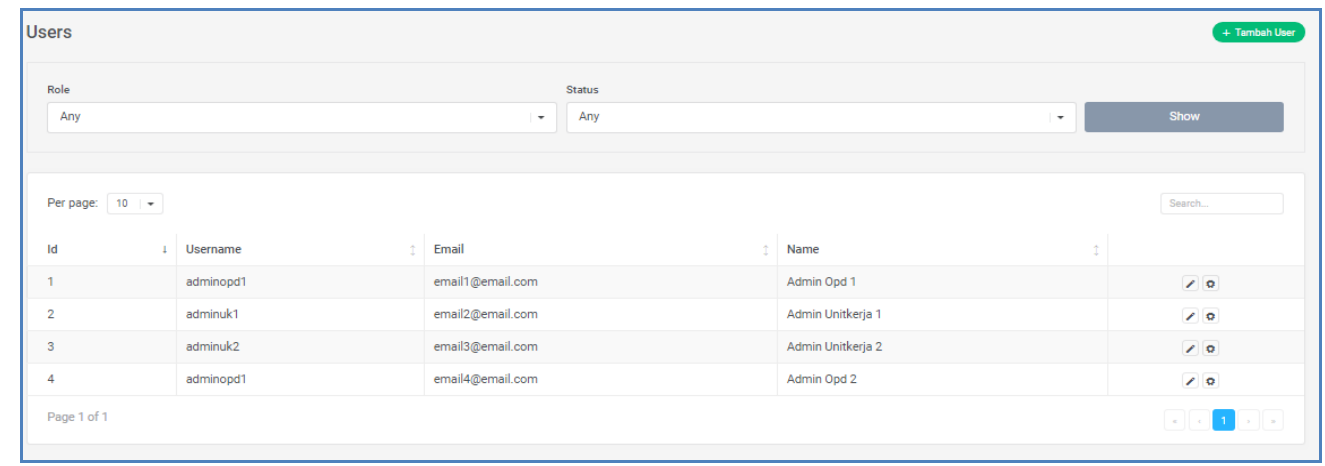

Gambar 12

Antar Muka Kelola User

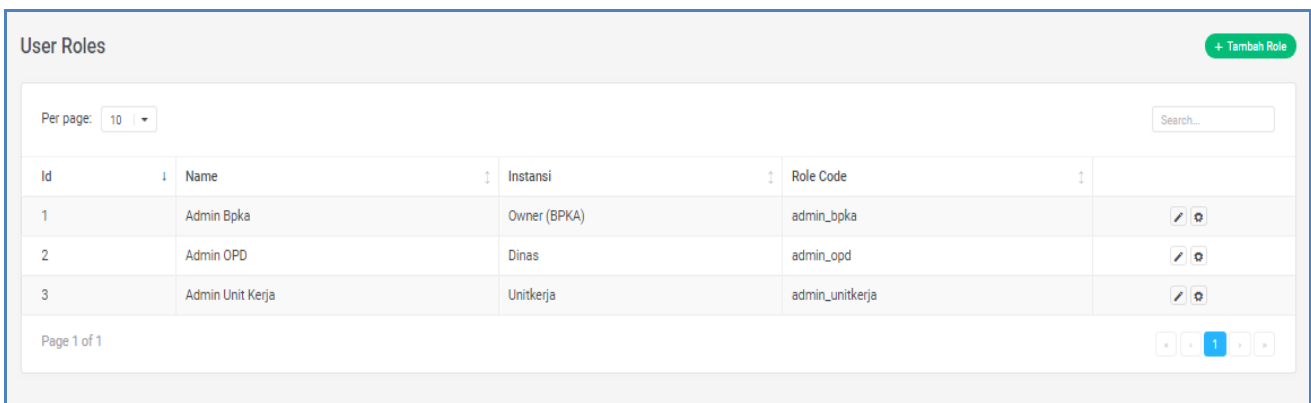

Gambar 13

Antar Muka User Role 


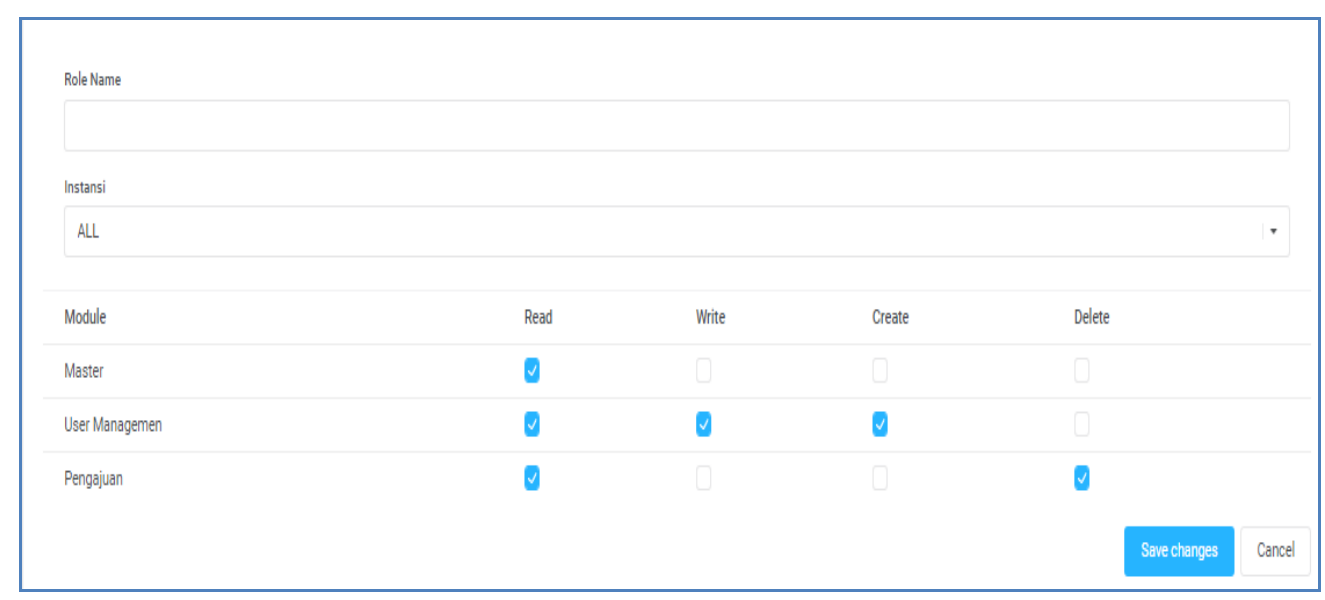

Gambar 14

Antar Muka Setting Role

\section{KESIMPULAN}

Aplikasi pencatatan dan pelaporan persediaan pakai habis ini diharapkan bisa membantu perangkat daerah yang ada di kota Bandung untuk menghasilkan laporan yang dibutuhkan sesuai PERWAL Kota Bandung No.17 Tahun 2019 yang mengharuskan penyerahan laporan atas arus masuk keluar barang persedian dilakukan per semester.

Kendala di jaringan internet juga diharapkan tidak menjadi hambatan dalam menggunakan aplikasi berbasis web ini. Kendala yang dimaksud yang diakibatkan baik karena masalah infrastruktur internet maupun beban koneksi khususnya di masa akhir semester.

BPKA selaku owner bahkan inspektorat sebagai salah satu stakeholder dari aplikasi ini bisa melihat secara live kondisi pergerakan barang persediaan. Adapun batasan dari sistem ini adalah belum tersedianya aplikasi dalam bentuk mobile app, walaupun aplikasi ini sudah mengadopsi responsive web app.

\section{DAFTAR PUSTAKA}

Tal Ater, Building Progressive Web Apps: Bringing the Power of Native to the Browser, 2017.

PERWAL Kota Bandung Nomor 17 tahun 2019. 